\title{
Analysis and Prediction of Total Retail Sales of Consumer Goods Based on Multiple Regression and SARIMA Model
}

\author{
Pengyue Xu \\ School of Business, Shandong University, Weihai Shandong, China
}

Keywords: Total retail sales of consumer goods; Multiple regression; SARIMA model; Time series

\begin{abstract}
In order to explore the influencing factors and prediction methods of total retail sales of consumer goods under the new normal of economy, this paper studies the time series data of China from 2007 to 2018, analyzes the influence of multiple economic variables on total retail sales of consumer goods by using multiple regression model, and uses seasonal autoregressive moving average model (SARIMA) to make high-precision fitting. The basis is provided for its short-term prediction, and finally the policy suggestions are given. The results show that the stock of money and quasi money (M2) and the state budget expenditure are positively correlated with the total retail sales of consumer goods; the total retail sales of social consumer goods in China will maintain a rapid growth trend in the future.
\end{abstract}

\section{Introduction}

The "Total Retail Sales of Consumer Goods" refers to the amount of non-production and nonbusiness goods which enterprises sell to individuals and social groups through the transaction, as well as providing food and beverage services. It is an important indicator to measure the level of consumption of residents. [1] It is generally believed in the academic circles that the key to increasing the total retail sales of consumer goods is to increase the per capita disposable income of residents.[2-4] The completion of fixed assets investment and financial expenditure also play a leading role in the total retail sales of consumer goods.[5-8] However, almost all of the above studies are based on the analysis of annual data, and the short-term prediction of the total retail sales of consumer goods is not satisfying.[9] Also, it is possible to relax the classical hypothesis test of linear regression in order to provide a higher model fit.

In order to effectively explain the influence factors of total retail sales of social consumer goods increase and forecast it in the short term, we choose a series of monthly economic indicators, using multiple linear regression method to establish a model and verify the classical assumptions, and then apply a SARIMA model to forecast the total retail sales of social consumer goods. In the end, we compare the two kinds of model prediction effect. It is found that money and quasi-money stock (M2) and national fiscal budget expenditure are positively correlated with the total retail sales of consumer goods, of which money and quasi-money stock (M2) have the strongest correlation; retail sales of consumer goods in China will continue to grow rapidly in the future.

\section{Sample Description, Model Setting and Variable Description}

From the perspective of economic theory and past academic research, influence factors of the total retail sales of social consumer goods (Y) include the money supply, household income, spending, etc. As residents' income for each quarter, its effectiveness in the short term is not significant for the prediction of interpreted variable prediction and policy guidance. So this paper chooses money and quasi money stock $\left(\mathrm{X}_{1}\right)$, the national budget expenditure $\left(\mathrm{X}_{2}\right)$, the national budget revenues $\left(\mathrm{X}_{3}\right)$, fixed asset investment $\left(\mathrm{X}_{4}\right)$, the market value of stock circulation $\left(\mathrm{X}_{5}\right)$ as explanatory variables, the other influential factors in random perturbation terms. The data used in this paper are all from the national bureau of statistics, China economic database (CEIC) and Tai'an database (CSMAR). In 2007, the fiscal revenue and expenditure subject carried out a big reform, especially the scope of fiscal expenditure item changed a lot, as a result, the previous data cannot be 
compared. Therefore, this paper selects the current value of the total retail sales of consumer goods in each month from 2007 to 2018. In order to eliminate the influence of the uncertain factors during the Spring Festival holiday and enhance the comparability of the data, the national bureau of statistics has not released the total retail sales of consumer goods in January and February since 2012, so there are currently $12 \times 10=120$ sample data.

Based on the above analysis, the multiple linear regression model is constructed as follows:

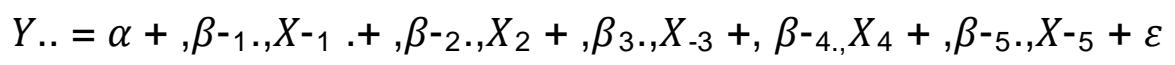

The descriptive statistical results of the data are shown in Table 1.

Table 1 Variable descriptive statistics

\begin{tabular}{|c|c|c|c|c|c|c|}
\hline name & $\begin{array}{c}\text { Variable } \\
\text { meaning }\end{array}$ & $\begin{array}{c}\text { Number of } \\
\text { observations }\end{array}$ & Average & $\begin{array}{c}\text { Standard } \\
\text { Deviation }\end{array}$ & Minimum & Maximum \\
\hline $\mathrm{Y}$ & $\begin{array}{c}\text { Total retail } \\
\text { sales of } \\
\text { consumer } \\
\text { goods }\end{array}$ & 120 & 19192.937 & 8355.400 & 6672.500 & 35893.500 \\
\hline $\mathrm{X}_{1}$ & $\mathrm{M} 2$ & 120 & 1025773.699 & 452430.434 & 364093.660 & 1826744.220 \\
\hline $\mathrm{X}_{2}$ & $\begin{array}{c}\text { State budget } \\
\text { financial } \\
\text { expenditure } \\
\text { Revenue } \\
\text { from the state } \\
\text { budget }\end{array}$ & 120 & 11938.305 & 6695.532 & 2874.200 & 37725.390 \\
\hline $\mathrm{X}_{3}$ & 120 & 9756.814 & 3902.299 & 3144.830 & 18472.930 \\
\hline $\mathrm{X}_{4}$ & $\begin{array}{c}\text { Fixed asset } \\
\text { investment }\end{array}$ & 120 & 36923.492 & 18196.483 & 8008.600 & 81273.000 \\
\hline $\mathrm{X}_{5}$ & $\begin{array}{c}\text { Market value } \\
\text { of shares } \\
\text { outstanding }\end{array}$ & 120 & 23230.541 & 13401.735 & 3770.600 & 50468.200 \\
\hline
\end{tabular}

\section{Empirical Results and Analysis}

\subsection{Correlation analysis}

Firstly, the Pearson correlation test and Spearman correlation test were performed on the data to ensure the effectiveness of the regression model, as shown in Table 2.

It can be seen that the total retail sales of consumer goods are significantly positively correlated with all explanatory variables, indicating that the selection of variables is reasonable. However, there is also a high correlation between explanatory variables, suggesting that multicollinearity may occur.

Table 2 Correlation analysis

\begin{tabular}{|c|c|c|c|c|c|c|}
\hline Model & $\mathrm{Y}$ & $\mathrm{X}_{1}$ & $\mathrm{X}_{2}$ & $\mathrm{X}_{3}$ & $\mathrm{X}_{4}$ & $\mathrm{X}_{5}$ \\
\hline $\mathrm{Y}$ & 1 & 0.991 & 0.846 & 0.859 & 0.949 & 0.928 \\
\hline $\mathrm{X}_{1}$ & 0.985 & 1 & 0.829 & 0.881 & 0.949 & 0.934 \\
\hline $\mathrm{X}_{2}$ & 0.738 & 0.711 & 1 & 0.661 & 0.839 & 0.708 \\
\hline $\mathrm{X}_{3}$ & 0.832 & 0.871 & 0.536 & 1 & 0.878 & 0.806 \\
\hline $\mathrm{X}_{4}$ & 0.926 & 0.935 & 0.732 & 0.871 & 1 & 0.903 \\
\hline $\mathrm{X}_{5}$ & 0.928 & 0.935 & 0.669 & 0.837 & 0.883 & 1 \\
\hline
\end{tabular}

Note: the lower-left part is the Pearson correlation coefficient, and the upper right part is the Spearman correlation coefficient. ${ }^{* *}$ indicates a significant correlation at the $1 \%$ level (doubletailed) 


\subsection{Model regression analysis}

Correlation analysis only analyses the interaction between two variables. In order to further explore the influencing factors of the total retail sales of consumer goods, multiple regression analysis is carried out to comprehensively consider the influence of various variables. The regression results after calculation are shown in Table 3.

It is obvious that the model has serious multicollinearity and redundant variables should be deleted. T-test was used to screen the independent variables and check the multiple regression results of the output. The double-tailed significances of $\mathrm{X}_{2}, \mathrm{X}_{4}$ and $\mathrm{X}_{5}$ are greater than 0.025 , indicating that the test failed.

Table 3 Multiple regression results (1)

\begin{tabular}{|c|c|c|c|c|c|c|}
\hline & Coefficient & Standard error & $\mathrm{t}$ & Significance & Allowance & VIF \\
\hline (Constant) & 1235.940 & 374.954 & 3.296 & 0.001 & & \\
\hline $\mathrm{X}_{1}$ & 0.017 & 0.001 & 16.987 & 0.000 & 0.067 & 14.954 \\
\hline $\mathrm{X}_{2}$ & 0.058 & 0.028 & 2.069 & 0.041 & 0.398 & 2.511 \\
\hline $\mathrm{X}_{3}$ & -0.251 & 0.071 & -3.536 & 0.001 & 0.185 & 5.418 \\
\hline $\mathrm{X}_{4}$ & 0.026 & 0.021 & 1.251 & 0.213 & 0.096 & 10.381 \\
\hline $\mathrm{X}_{5}$ & 0.043 & 0.025 & 1.684 & 0.095 & 0.123 & 8.101 \\
\hline \multicolumn{3}{|c|}{$\mathrm{R}^{2}=0.977$} & \multicolumn{4}{|c|}{$\mathrm{R}^{2}(\mathrm{adj})=0.976$} \\
\hline \multicolumn{3}{|c|}{ Standard Error = 1299.954} & \multicolumn{4}{|c|}{ Durbin-Watson $=1.409$} \\
\hline \multicolumn{3}{|c|}{$F=960.431$} & \multicolumn{4}{|c|}{$\mathrm{P}=0.000^{\mathrm{b}}$} \\
\hline
\end{tabular}

After deleting $\mathrm{X}_{4}$ and $\mathrm{X}_{5}$ successively, the new regression results are obtained in Table 4 . The adjusted $\mathrm{R}^{2}$ is 0.975 , indicating that the model constructed in this paper has a high fitting degree. The $\mathrm{F}$ value increases significantly after the redundant variables are removed, indicating that the explanatory ability is further enhanced. VIF values are all less than 10 , so multicollinearity is at an acceptable level.

The estimated regression equation is:

$$
Y .=1235.94+0.017 ., X_{-1} .+, 0.058 X_{2}-0.251 X_{-3}
$$

If we know the stock of money and quasi-money (M2), the state budget expenditure and the state budget revenue in a given month, we can now estimate or predict the total retail sales of consumer goods in that month. The above mechanism can be understood as that the nominal money circulation enters the social consumption cycle after it is partly precipitated by the state budget fiscal expenditure and the state budget fiscal revenue, which is the so-called state savings.

Table 4 Multiple regression results (2)

\begin{tabular}{|c|c|c|c|c|c|c|}
\hline & Coefficient & Standard error & $\mathrm{t}$ & Significance & Allowance & VIF \\
\hline (Constant) & 849.62 & 330.769 & 2.569 & 0.011 & & \\
\hline $\mathrm{X}_{1}$ & 0.019 & 0.001 & 28.131 & 0.000 & 0.156 & 6.392 \\
\hline $\mathrm{X}_{2}$ & 0.074 & 0.026 & 2.796 & 0.006 & 0.465 & 2.151 \\
\hline $\mathrm{X}_{3}$ & -0.200 & 0.065 & -3.084 & 0.003 & 0.226 & 4.433 \\
\hline \multicolumn{3}{|c|}{$\mathrm{R}^{2}=0.976$} & \multicolumn{4}{|c|}{$\mathrm{R}^{2}(\mathrm{adj})=0.975$} \\
\hline \multicolumn{3}{|c|}{ Standard Error = 1313.684} & \multicolumn{4}{|c|}{ Durbin-Watson $=1.329$} \\
\hline \multicolumn{3}{|c|}{$F=1565.976$} & \multicolumn{4}{|c|}{$\mathrm{P}=0.000^{\mathrm{b}}$} \\
\hline
\end{tabular}




\subsection{Parameter Test}

\subsubsection{Overall hypothesis test}

Firstly, the overall hypothesis test of the model was conducted to observe whether all regression coefficients were equal to 0 at the significance level of 0.05 . The null hypothesis and the alternative hypothesis are

$\mathrm{H}_{0}:, \beta_{-1 .,}=\beta_{-2,}=\beta_{-3 .,}=0$

$\mathrm{H}_{1}$ : Not all regression coefficients are equal to 0 .

The significance level in the output is 0.000 . Since the significance level is less than the preset 0.05 , we reject the null hypothesis that these regression coefficients are not all 0 .

\subsubsection{Single variable hypothesis test}

Then we evaluate a single regression coefficient, and use the t-value in the output results to test each regression coefficient. The null hypothesis and the alternative hypothesis are

$\mathrm{H}_{0}:, \beta_{\text {-i., }}=0$

$\mathrm{H}_{1}:, \beta_{\text {-i., }} \neq 0$

Subscript I represents any independent variables using the same 0.05 significant level. For money and quasi money stock (M2), the state financial budget spending and state budget income, the regression coefficient of p- value is less than 0.01 , which shows that the coefficient is not equal to 0 , and has significant effect to predict total retail sales of social consumer goods.

\subsubsection{Linear regression hypothesis test}

Next, we use our regression model to verify the assumption of linear regression. The first assumption is that there is a linear relationship between each independent variable and each dependent variable.

Use $\mathrm{y}$ as the vertical axis, $\mathrm{X}_{1}, \mathrm{X}_{2}$ and $\mathrm{X}_{3}$ as the horizontal axis to construct the scatter diagram, as shown in Figure 1.

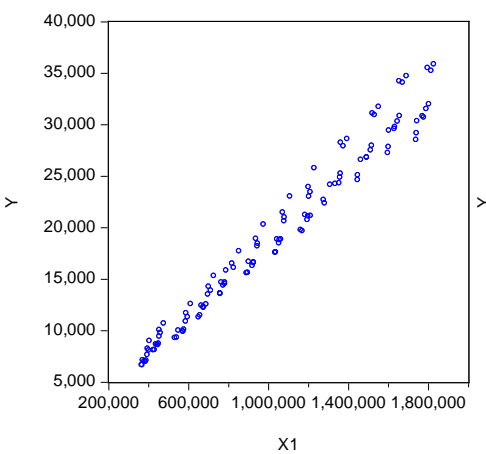

$\mathrm{x} 1$

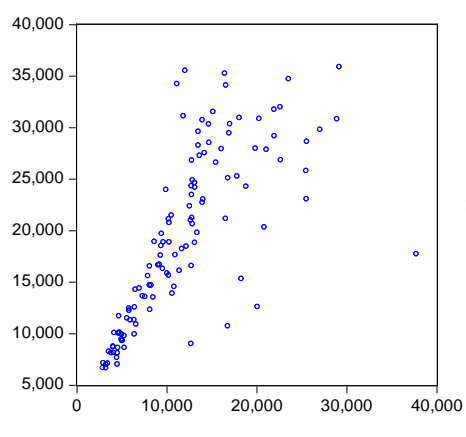

X2

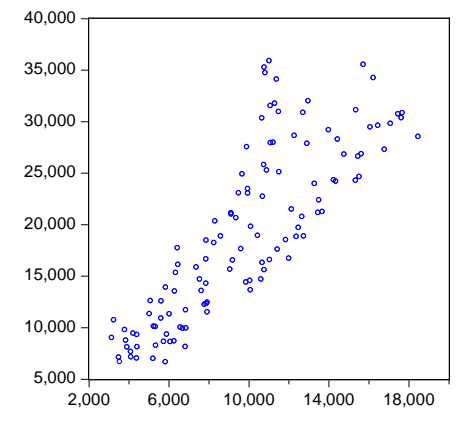

Figure $1 \mathrm{X}$-Y scatter plot

Total retail sales of social consumer goods for money and quasi money stock (M2) and the state financial budget expenditure presents the overall growth trend. As the increase of money and quasi money stock (M2) or the state budget expenditure, total retail sales of social consumer goods increase at the same time, indicating that the relationship is linear. Obviously, there are no nonlinear characteristics in the data above.

\subsection{Test and remedy of heteroscedasticity}

\subsubsection{Graphic test}

Take the square of the regression RESID ${ }^{2}$ as the ordinate and an explanatory variable $\mathrm{X}_{\mathrm{i}}$ in the regression equation as the abscissa, drawing a scatter diagram. If the scatter chart shows a certain trend, the heteroscedasticity can be judged. 

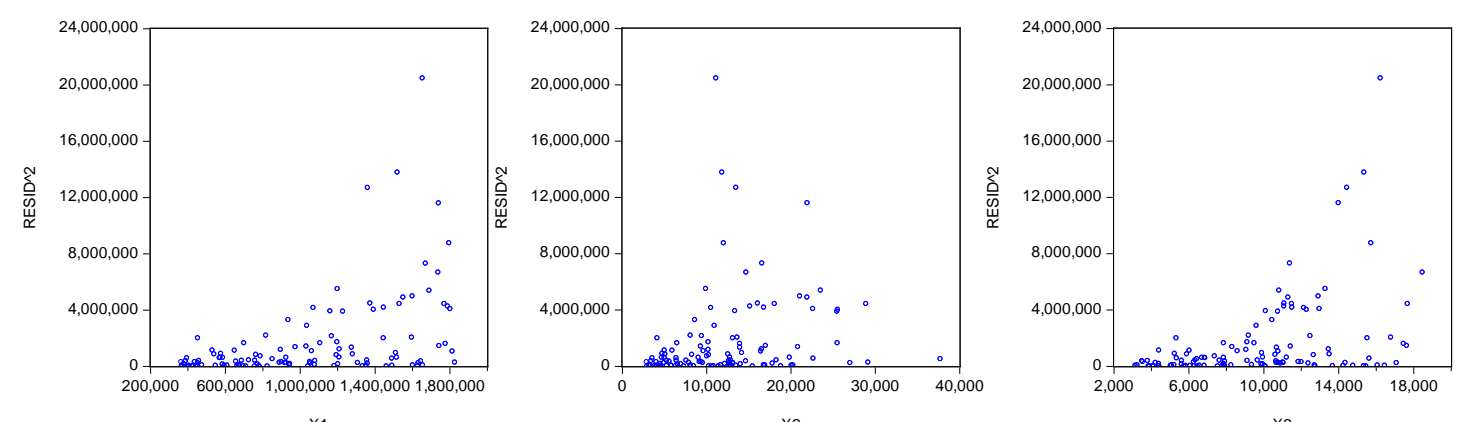

Figure 2 Residual scatter plot

As shown in Figure 2, the residual distribution is flared, suggesting that heteroscedasticity may exist.

\subsubsection{White test}

White test is provided by $\mathrm{H}$. White in 1980, the heteroscedasticity test of which carried out by constructing an auxiliary regression and using the $\chi 2$ statistic. The null hypothesis and alternative hypothesis tested by White are:

$\mathrm{H}_{0}:, \varepsilon$ has no heteros

$\mathrm{H}_{1}:, \varepsilon$ has heteros

The test results are shown in Table 5 . As the sample number is 120 , the determination coefficient $\mathrm{nR} 2$ of the auxiliary regression function can be calculated as 43.501. Under the null hypothesis, $\mathrm{nR}^{2}$ asymptotic is subject to the $\chi^{2}$ distribution with 9 degrees of freedom, and the critical value $\chi_{a}{ }^{2}(9)$ is 16.919 when $\alpha=0.05$, which is less than $\mathrm{nR}^{2}$. The null hypothesis is rejected, indicating that the random error in the model has heteroscedasticity.

Table 5 Outcome of white test

\begin{tabular}{|c|c|c|c|c|}
\hline & Coefficient & Standard error & $\mathrm{t}$ & Significance \\
\hline Constant & -443838.6 & 1540346 & -0.288 & 0.772 \\
\hline $\mathrm{X}_{1}^{2}$ & $-1.03 E-05$ & $5.28 \mathrm{E}-06$ & -1.961 & 0.053 \\
\hline $\mathrm{X}_{1} * \mathrm{X}_{2}$ & $6.20 \mathrm{E}-05$ & 0.000 & 0.188 & 0.851 \\
\hline $\mathrm{X}_{1} * \mathrm{X}_{3}$ & 0.004 & 0.001 & 3.702 & 0.000 \\
\hline $\mathrm{X}_{1}$ & -13.802 & 7.553 & -1.827 & 0.070 \\
\hline $\mathrm{X}_{2}{ }^{2}$ & 0.005 & 0.006 & 0.886 & 0.377 \\
\hline $\mathrm{X}_{2} * \mathrm{X}_{3}$ & -0.038 & 0.031 & -1.228 & 0.222 \\
\hline $\mathrm{X}_{2}$ & 37.536 & 227.782 & 0.165 & 0.869 \\
\hline $\mathrm{X}_{3}{ }^{2}$ & -0.259 & 0.078 & -3.316 & 0.001 \\
\hline $\mathrm{X}_{3}$ & 1417.578 & 691.708 & 2.049 & 0.043 \\
\hline \multicolumn{2}{|c|}{$\mathrm{R}^{2}=0.363$} & \multicolumn{3}{|c|}{$\mathrm{R}^{2}(\operatorname{adj})=0.310$} \\
\hline \multicolumn{2}{|c|}{ Standard Error $=2533558$} & \multicolumn{3}{|c|}{ Durbin-Watson $=1.962$} \\
\hline \multicolumn{2}{|c|}{$F=6.950$} & & \multicolumn{2}{|c|}{$\mathrm{P}=0.000^{\mathrm{b}}$} \\
\hline
\end{tabular}

\subsubsection{Weighted least square estimation}

When there is heteroskedasticity in the model, it can be proved that the estimator of the ordinary least square method is still linear and unbiased, but it no longer has the minimum variance, that is, the estimator is no longer valid. In this paper, $\mathrm{w}_{1}=1 / \operatorname{sqr}\left(\mathrm{X}_{1} * \mathrm{X}_{3}\right)$ is selected as the weight by using the weighted least squares estimation method to calculate the predicted value of regression standardization and the residual of regression standardization, constructing a new residual diagram. 
The result is shown in Table 6 .

Table 6 Improved multiple regression results (1)

\begin{tabular}{|c|c|c|c|c|}
\hline & Coefficient & Standard error & $\mathrm{t}$ & Significance \\
\hline (Constant) & 669.396 & 182.141 & 3.675 & 0.000 \\
\hline $\mathrm{X}_{1}$ & 0.018 & 0.001 & 29.472 & 0.000 \\
\hline $\mathrm{X}_{2}$ & 0.097 & 0.018 & 5.307 & 0.000 \\
\hline $\mathrm{X}_{3}$ & -0.132 & 0.059 & -2.248 & 0.027 \\
\hline \multicolumn{3}{|c|}{$\mathrm{R}^{2}=0.985$} & \multicolumn{2}{|c|}{$\mathrm{R}^{2}(\mathrm{adj})=0.984$} \\
\hline \multicolumn{3}{|c|}{ Standard Error $=959.333$} & \multicolumn{2}{|c|}{ Durbin-Watson = 1.198} \\
\hline \multicolumn{3}{|c|}{$F=2479.750$} & \multicolumn{2}{|c|}{$\mathrm{P}=0.000^{\mathrm{b}}$} \\
\hline
\end{tabular}

At this point, the $\mathrm{P}$ value of $\mathrm{X}_{3}$ is greater than 0.025 , which cannot meet the requirements of the T-test of a single variable, so the variable is removed. A new regression model is obtained. According to the conclusion of the White test, $\mathrm{w}_{2}=1 / \mathrm{X}_{1}$ is used as the weight to re-evaluate the weighted least squares estimation. The analysis result is summarized in Table 7.

Table 7 Improved multiple regression results (2)

\begin{tabular}{|c|c|c|c|c|}
\hline & Coefficient & Standard error & $\mathrm{t}$ & Significance \\
\hline (Constant) & 523.928 & 162.896 & 3.216 & 0.002 \\
\hline $\mathrm{X}_{1}$ & 0.017 & 0.000 & 53.662 & 0.000 \\
\hline $\mathrm{X}_{2}$ & 0.111 & 0.019 & 5.854 & 0.000 \\
\hline \multicolumn{2}{|c|}{$\mathrm{R}^{2}=0.982$} & \multicolumn{3}{c|}{$\mathrm{R}^{2}(\mathrm{adj})=0.982$} \\
\hline \multicolumn{2}{|c|}{ Standard Error $=926.248$} & $\mathrm{P}=0.000^{\mathrm{b}}$ \\
\hline
\end{tabular}

It can be seen that the value of the F statistic of the re-improved model is increased to 3249.748, indicating that the steps to eliminate heteroscedasticity have successfully optimized the model.

The White test of the model shows that $\mathrm{nR}^{2}$ was reduced to 5.662 , and the critical value $\chi_{\alpha}{ }^{2}(2)$ at the significance level of 0.05 was 5.991. $\mathrm{nR}^{2}$ was less than the critical value, indicating that heteroscedasticity had been removed successfully.

\subsection{Verification and remediation of sequence correlation}

\subsubsection{Durbin-watson test}

According to Table 7, the Durbin-Watson test value of the model is 0.967 . For the model of the two explanatory variables and the significance level of 5\%, we can see from the DW critical value table that, when $n=100, d L=1.634, d U=1.715$, when $n=150, d L=1.706, d U=1.715$. As the sample size is 120 , the model has a sequence correlation.

\subsubsection{Correlation graph and ljung-box $Q$ statistic test}

In order to further confirm the existence of sequence correlation in the model, we can use the estimated autocorrelation coefficient and partial autocorrelation coefficient of the regression equation's residual sequence, as well as the Ljung-Box Q statistic to test. The area between the dotted lines is sandwiched by plus or minus twice the estimated standard deviation. If the autocorrelation value is in this range, it can be considered that there is no significant difference from the null hypothesis at the significance level of 5\%. In Figure 3, the autocorrelation coefficient and the partial correlation coefficient both exceed the dotted line, so the residual sequence has a sequence correlation. 


\begin{tabular}{|c|c|c|c|c|c|c|}
\hline Autocorrelation & Partial Correlation & & $A C$ & PAC & Q-Stat & Prob \\
\hline$\square$ & $1 \longmapsto$ & 1 & 0.512 & 0.512 & 32.304 & 0.000 \\
\hline ， 口 & 다 1 & 2 & 0.124 & -0.187 & 34.222 & 0.000 \\
\hline 口أ & $\square$ । & 3 & -0.198 & -0.249 & 39.109 & 0.000 \\
\hline$\square$ & 回 । & 4 & -0.332 & -0.134 & 53.055 & 0.000 \\
\hline$\square 1$ & । & 5 & -0.199 & 0.089 & 58.119 & 0.000 \\
\hline$\square$ & $\square$ & 6 & -0.370 & -0.504 & 75.726 & 0.000 \\
\hline
\end{tabular}

Figure 3 Residual sequence correlation diagram

\subsubsection{Breush-godfrey LM test}

Breush-Godfrey LM test can also be used to test whether there is a higher-order autocorrelation in the residual sequence of the regression equation. The original assumption is that there is no sequence correlation until the p-order lag, as $\mathrm{P}$ is a pre-defined integer; the alternative hypothesis is that there is an autocorrelation of order p. Using the $\mathrm{LM}$ test, the F statistic was 21.452 , the $\mathrm{T} \times \mathrm{R}^{2}$ statistic was 32.605 , and the p-values were all less than 0.0001 , indicating the existence of sequence correlation.

\subsubsection{Cochrane-orcutt iterative method}

To eliminate sequence correlation, the Cochrane-Orcutt iterative method can be used. According to the results obtained by the Ljung-Box Q statistical test method, we can judge that the residual of the equation has an autocorrelation in order 1, order 3 and order 6 of hysteresis. We modified the model and got the result as shown in Figure 4.

\begin{tabular}{|c|c|c|c|c|c|}
\hline Autocorrelation & Partial Correlation & $\mathrm{AC}$ & PAC & Q-Stat & Prob* \\
\hline 1디 1 & 1디 & $1-0.102$ & -0.102 & 1.2911 & \\
\hline । & । & $2-0.043$ & -0.054 & 1.5212 & \\
\hline ו ו & 1 & 30.120 & 0.111 & 3.3229 & \\
\hline $1 \sqrt{1}$ & $1 \sqrt{1}$ & $4-0.044$ & -0.023 & 3.5726 & 0.059 \\
\hline $1 口$ & $1 口$ & 50.164 & 0.171 & 6.9804 & 0.030 \\
\hline$1 \longdiv { 1 }$ & 1 屋 & $\begin{array}{ll}6 & 0.073\end{array}$ & 0.095 & 7.6717 & 0.053 \\
\hline 1 & 10 & $7-0.099$ & -0.063 & 8.9438 & 0.063 \\
\hline 回 & $\square$ । & $8-0.146$ & -0.207 & 11.732 & 0.039 \\
\hline
\end{tabular}

Figure 4 The modified residual sequence correlation diagram

It can be seen from the above figure that the $\mathrm{P}$ values of the $\mathrm{Q}$ statistic of each order of hysteresis are above the critical value specified by the $5 \%$ significance level, indicating that the residual sequence has no sequence correlation. The final multiple regression analysis result is obtained, which is included in Table 8.

Table 8 The final result of multiple regression

\begin{tabular}{|c|c|c|c|c|}
\hline & Coefficient & Standard error & $\mathrm{t}$ & Significance \\
\hline (Constant) & 448.047 & 276.048 & 1.623 & 0.107 \\
\hline $\mathrm{X} 1$ & 0.017 & 0.000 & 58.916 & 0.000 \\
\hline $\mathrm{X} 2$ & 0.083 & 0.016 & 5.052 & 0.000 \\
\hline \multicolumn{2}{|c|}{$\mathrm{R}^{2}=0.986$} & \multicolumn{3}{c|}{$\mathrm{R}^{2}(\mathrm{adj})=0.985$} \\
\hline \multicolumn{2}{|c|}{$\mathrm{P}=1341.780$} & $\mathrm{P}=0.000^{\mathrm{b}}$ \\
\hline
\end{tabular}

To sum up, the multiple regression equation is

$Y .=458.047+0.017 ., X-_{-1}+, 0.083 X_{2}$ 
This equation explains $98.6 \%$ of the total variation of the total retail sales of consumer goods, and it does not violate the linear assumption of multiple regression, residual normal distribution assumption, non-multicollinearity assumption, homo-variance assumption, and non-autocorrelation assumption.

\section{SARIMA Model's Prediction of Total Retail Sales of Consumer Goods}

\subsection{Application of model}

\subsubsection{Unit root test for nonstationary sequences}

In the field of time series analysis, the ARMA model, ARIMA model and SARIMA model proposed by Box-Jenkins are the commonly used short-term analysis and prediction tools. ARMA(p, q) model is a hybrid model of $\mathrm{AR}(\mathrm{p})$ and $\mathrm{MA}(\mathrm{q})$, which is only suitable for describing the autocorrelation of a stationary series.[10] If the time series are non-stationary, the stationary sequence should be obtained by difference operation before the model is established.[11]

The ADF test method controls the correlation of higher-order sequences by adding the lagged difference term of the explained variable to the right side of the regression equation:

$$
\begin{gathered}
\Delta y_{t}=\eta y_{t-1}+\sum_{i=1}^{p-1} \beta_{i} \Delta y_{t-i}+u_{t}, \quad t=1,2, \ldots, T \\
\Delta y_{t}=\eta y_{t-1}+a+\sum_{i=1}^{p-1} \beta_{i} \Delta y_{t-i}+u_{t}, \quad t=1,2, \ldots, T \\
\Delta y_{t}=\eta y_{t-1}+a+\delta t+\sum_{i=1}^{p-1} \beta_{i} \Delta y_{t-i}+u_{t}, \quad t=1,2, \ldots, T
\end{gathered}
$$

In the ADF test of total retail sales of consumer goods, the lag period required to eliminate sequence correlation was determined to be 12 according to SIC criterion, and the test results show that its $\mathrm{ADF}$ statistic is -2.536876 , which is greater than the critical value of three different significance levels $(1 \%,-4.046072 ; 5 \%, 3.452358 ; 10 \%,-3.151673)$. Therefore, the time series is non-stationary.

\subsubsection{Logarithmic difference transformation}

In order to eliminate the heteroscedasticity of time series easily, we first perform logarithmic treatment on the original data ser01 to obtain a new time series ser02 and make a difference at the same time.

The unit root test of time series ser02 shows that the ADF test value of ser02 is -3.848948 , which is still greater than the critical value of three different significance levels (1\%, $-4.048682 ; 5 \%$, $3.453601 ; 10 \%,-3.152400)$, indicating that the unit root still exists after the first difference.

We perform the difference processing on the time series again and test the time series after the difference by ADF. Finally, the time series d2ser02 is obtained after two differences. The test result shows that $\mathrm{ADF}=-9.303401$, less than the critical value of three different significance levels (1\%, 4.046072; 5\%, 3.452358; $10 \%,-3.151673)$, and the $\mathrm{p}$-value is less than 0.0001 . The conclusion that there is no unit root is accepted. Therefore, it can be determined that the sequence of total retail sales of consumer goods is an integer sequence of order 2, which means that the total retail sales of consumer goods of society $\sim \mathrm{I}(2)$. By drawing a line graph as shown in Figure 5, it can be seen that the trend of time series has been basically eliminated. 


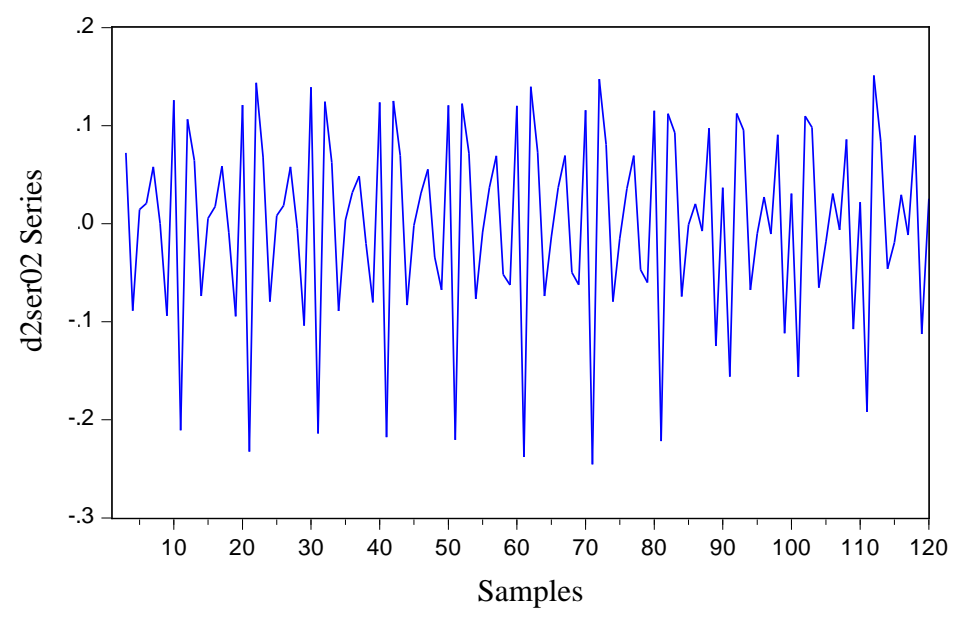

Figure 5 Second-order differential time series line graph

\subsubsection{SARIMA model identification}

Through two difference operations on ser01 data, we can find from the correlation diagram of time series d2ser02 in Figure 6 that when $\mathrm{k}=10$ or 20, the autocorrelation coefficient will show a relatively large peak, indicating that the sequence contains a certain seasonality, where further seasonal difference is needed. We make a seasonal difference of period $S=10$ for d2ser02, and the correlation diagram after the difference is shown in Figure 7. The autocorrelation coefficient and partial correlation coefficient of the time series fall into the random region quickly, and the sequence trend is basically eliminated. However, when $\mathrm{k}=10$ or 20 , the value is still large, and the seasonality is not completely eliminated. The second seasonal difference is made, and it is found that the seasonality did not continue to improve, so the first-order seasonal difference was finally adopted.

The recognition rule of the time series model is as follows: (1) if the partial autocorrelation coefficient of the stationary time series shows a certain attenuated towing feature, and the autocorrelation function is truncated, it can be judged that it follows a MA(q) process. (2) if the autocorrelation coefficient of the stationary time series shows a certain attenuated towing feature, and the partial autocorrelation coefficient is truncated, it can be judged that it follows an AR(p) process. (3) it is applicable to the $\operatorname{ARIMA}(\mathrm{p}, \mathrm{d}, \mathrm{q})$ model if both autocorrelation function and partial autocorrelation function show a certain attenuation towing feature.[12,13]

\begin{tabular}{|c|c|c|c|c|c|}
\hline Autocorrelation & Partial Correlation & $\mathrm{AC}$ & PAC & Q-Stat & Prob \\
\hline$\square 1$ & 1 & $1-0.543$ & -0.543 & 35.661 & 0.000 \\
\hline $1 \|$ & $\square$ & $2-0.021$ & -0.447 & 35.715 & 0.000 \\
\hline । 口 & $\square$ । & $3 \quad 0.124$ & -0.240 & 37.605 & 0.000 \\
\hline 吅 1 & $\square 1$ & $4-0.129$ & -0.304 & 39.665 & 0.000 \\
\hline । 口 & 吅 1 & 50.133 & -0.134 & 41.887 & 0.000 \\
\hline 吅। & 口। & $6-0.115$ & -0.214 & 43.570 & 0.000 \\
\hline 1 1 & 1 [1 1 & $\begin{array}{ll}7 & 0.108\end{array}$ & -0.052 & 45.045 & 0.000 \\
\hline 111 & 1 । 1 & $8-0.016$ & 0.034 & 45.078 & 0.000 \\
\hline 1 & - 1 & $9-0.486$ & -0.888 & 75.743 & 0.000 \\
\hline 1 E & । I । & $10 \quad 0.891$ & -0.065 & 179.92 & 0.000 \\
\hline 1 & 101 & $11-0.487$ & -0.038 & 211.31 & 0.000 \\
\hline 101 & 111 & $12-0.022$ & 0.020 & 211.38 & 0.000 \\
\hline । 口 & 1 | 1 & $13 \quad 0.131$ & 0.039 & 213.69 & 0.000 \\
\hline 吅 । & 101 & $14-0.137$ & 0.061 & 216.26 & 0.000 \\
\hline ו ו & । [1 । & $15 \quad 0.116$ & -0.080 & 218.12 & 0.000 \\
\hline । व्य । & । [ । & $16-0.084$ & -0.047 & 219.10 & 0.000 \\
\hline । & । I । 1 & $17 \quad 0.088$ & -0.049 & 220.18 & 0.000 \\
\hline 11 & । [ । 1 & $18-0.012$ & -0.041 & 220.20 & 0.000 \\
\hline 1 & 101 & $19-0.434$ & -0.030 & 247.10 & 0.000 \\
\hline $1 \square$ & । 1 । & $20 \quad 0.789$ & -0.067 & 337.00 & 0.000 \\
\hline
\end{tabular}

Figure 6 d2ser02 related diagram 


\begin{tabular}{|c|c|c|c|c|c|}
\hline Autocorrelation & Partial Correlation & $A C$ & PAC & Q-Stat & Prob \\
\hline$\square 1$ & $\square$ & $1-0.463$ & -0.463 & 23.777 & 0.000 \\
\hline$\square$ । & 1 & $2-0.255$ & -0.597 & 31.087 & 0.000 \\
\hline $1 \square$ & $\sqsubset$ & $\begin{array}{ll}3 & 0.347\end{array}$ & -0.235 & 44.673 & 0.000 \\
\hline 吅 । & $\square$ । & $4-0.139$ & -0.294 & 46.889 & 0.000 \\
\hline 1 & 101 & $\begin{array}{ll}5 & 0.069\end{array}$ & 0.048 & 47.439 & 0.000 \\
\hline । & । & $6-0.101$ & -0.136 & 48.626 & 0.000 \\
\hline 111 & 1미 & $7-0.005$ & -0.120 & 48.629 & 0.000 \\
\hline ， 口 & । 1] । & 80.156 & -0.059 & 51.505 & 0.000 \\
\hline 1 & 11 & $9-0.125$ & -0.014 & 53.394 & 0.000 \\
\hline 111 & 11 & $10-0.011$ & -0.015 & 53.408 & 0.000 \\
\hline 1 & । 1 । & $11 \quad 0.054$ & -0.034 & 53.759 & 0.000 \\
\hline । [ । & 吅 । & $12-0.064$ & -0.147 & 54.259 & 0.000 \\
\hline । & । & $13 \quad 0.063$ & -0.110 & 54.757 & 0.000 \\
\hline । 1 1 1 & 미 & $14-0.058$ & -0.182 & 55.188 & 0.000 \\
\hline 111 & 10 1 & $15 \quad 0.023$ & -0.113 & 55.254 & 0.000 \\
\hline 1 1 & । [ 1 & $16 \quad 0.061$ & -0.065 & 55.732 & 0.000 \\
\hline । 1 । & । 1 1 1 & $17-0.084$ & -0.045 & 56.646 & 0.000 \\
\hline 1$] 1$ & । & $18 \quad 0.016$ & -0.088 & 56.681 & 0.000 \\
\hline 111 & । & $19 \quad 0.025$ & -0.105 & 56.765 & 0.000 \\
\hline । 1 । 1 & 口' & $20-0.064$ & -0.244 & 57.323 & 0.000 \\
\hline
\end{tabular}

Figure 7 Correlation diagram of d2ser02 after seasonal difference

After the above analysis, SARIMA(p, d, q)(P, D, Q)S model is selected to predict the total retail sales of consumer goods, where $d$ and $D$ are the order of difference. From the above judgment, we can know that $d=2$ and $d=1$. By observing the correlation graph of sales sequence (the sequence obtained after two difference and one seasonal difference), we can gain $p \in\{0,1,2,3,4\}$ and $q \in\{0$, $1,2,3\}$ from the distribution of autocorrelation coefficient and partial autocorrelation coefficient. Since there is no large peak of autoregressive coefficient and partial autoregressive coefficient when $\mathrm{K}=10$, we use $\mathrm{P}=\{0,1\}$ and $\mathrm{Q}=\{0,1\}$, but $\mathrm{p}, \mathrm{q}, \mathrm{P}$ and $\mathrm{Q}$ cannot be 0 at the same time. For the sake of accuracy, $5 \times 4 \times 2 \times 2-1=79$ models are established respectively. In addition, the combinations of $\mathrm{p}, \mathrm{d}$, $\mathrm{q}, \mathrm{P}, \mathrm{D}, \mathrm{Q}$ that fail t-test and the combinations whose residual is not white noise are removed. After that, there are still 4 combinations left.

\subsubsection{Order determination and parameter estimation}

The possible models obtained from the above information are $\operatorname{SARIMA}(3,2,0)(0,1,0)^{\mathrm{S}}$, $\operatorname{SARIMA}(4,2,0)(0,1,0)^{\mathrm{S}}, \operatorname{SARIMA}(4,2,1)(1,1,0)^{\mathrm{S}}, \operatorname{SARIMA}(4,2,1)(0,1,1)^{\mathrm{S}}$, The results of software inspection are summarized in Table 9.

Table 9 Parameter estimation and test results of different models

\begin{tabular}{|c|c|c|c|}
\hline The alternative model & AIC & SC & Std \\
\hline SARIMA(3, 2, 0)(0, 1, 0) & -5.375 & -5.251 & 0.023 \\
\hline SARIMA $(4,2,0)(0,1,0)^{10}$ & -5.444 & -5.295 & 0.023 \\
\hline SARIMA $(4,2,1)(1,1,0)^{10}$ & -5.440 & -5.241 & 0.027 \\
\hline SARIMA $(4,2,1)(0,1,1)^{10}$ & -5.432 & -5.234 & 0.023 \\
\hline
\end{tabular}

In order to select the model with the best statistical properties, we select the set of orders with the lowest AIC value and SC value as the best order according to the AIC criterion and Schwarz criterion. SARIMA $(4,2,0)(0,1,0)^{10}$ model are less than those of other SARIMA(p, d, q)(P, D, Q $)^{S}$ model in the AIC and SC values. Therefore, we choose SARIMA(4, 2, 0)(0, 1, 0$)^{10}$ model.

\subsubsection{Diagnostic analysis and testing}

Firstly, the residual analysis of the model is carried out. If the time series model is significantly effective, it needs to pass the white noise test, so the values in the residual ACF graph and PACF graph should fall into the random interval.[14] Figure 8 shows that model SARIMA(4, 2, 0)(0, 1, $0)^{10}$ is a white noise sequence, which can be used for fitting and prediction. The model fitting 
diagram is shown in Figure 9.

\begin{tabular}{|c|c|c|c|c|c|c|}
\hline Autocorrelation & Partial Correlation & & $A C$ & PAC & Q-Stat & Prob \\
\hline $1 \mid 1$ & $1 \mid 1$ & 1 & 0.005 & 0.005 & 0.0033 & \\
\hline 10 1 1 & 1 d 1 & & -0.037 & -0.037 & 0.1597 & \\
\hline 101 & 101 & 3 & -0.035 & -0.034 & 0.2968 & \\
\hline । 1 & 10 1 & & -0.103 & -0.104 & 1.5008 & \\
\hline । 1ํㅣ & 1] 1 & & -0.076 & -0.080 & 2.1740 & 0.140 \\
\hline । 1 & । 1 & & -0.106 & -0.118 & 3.4758 & 0.176 \\
\hline 1 & 101 & 7 & 0.049 & 0.033 & 3.7551 & 0.289 \\
\hline 11 & 11 & 8 & 0.016 & -0.010 & 3.7866 & 0.436 \\
\hline 10 1 & 1 ' & 9 & -0.094 & -0.119 & 4.8569 & 0.434 \\
\hline 屾 1 & 면 1 & 10 & -0.130 & -0.167 & 6.9197 & 0.328 \\
\hline 1니 1 & 1 & 11 & -0.094 & -0.130 & 7.9937 & 0.333 \\
\hline 10 & 回 1 & 12 & -0.103 & -0.158 & 9.3177 & 0.316 \\
\hline 111 & 1] 1 & 13 & 0.018 & -0.047 & 9.3567 & 0.405 \\
\hline 1 & 101 & 14 & 0.005 & -0.096 & 9.3597 & 0.498 \\
\hline 1 & 11 1 & 15 & 0.068 & -0.047 & 9.9455 & 0.535 \\
\hline 11 & 1 & 16 & -0.002 & -0.117 & 9.9459 & 0.621 \\
\hline । 1 1 1 & 면 1 & 17 & -0.052 & -0.145 & 10.305 & 0.669 \\
\hline 10 & 吼 1 & 18 & -0.020 & -0.136 & 10.359 & 0.735 \\
\hline 1 & 11 & 19 & 0.083 & -0.015 & 11.269 & 0.733 \\
\hline 1 1 & $1 \mid 1$ & 20 & 0.110 & 0.000 & 12.914 & 0.679 \\
\hline
\end{tabular}

Figure 8 SARIMA(4, 2, 0) $(0,1,0)^{10}$ Correlation graph of residual sequence

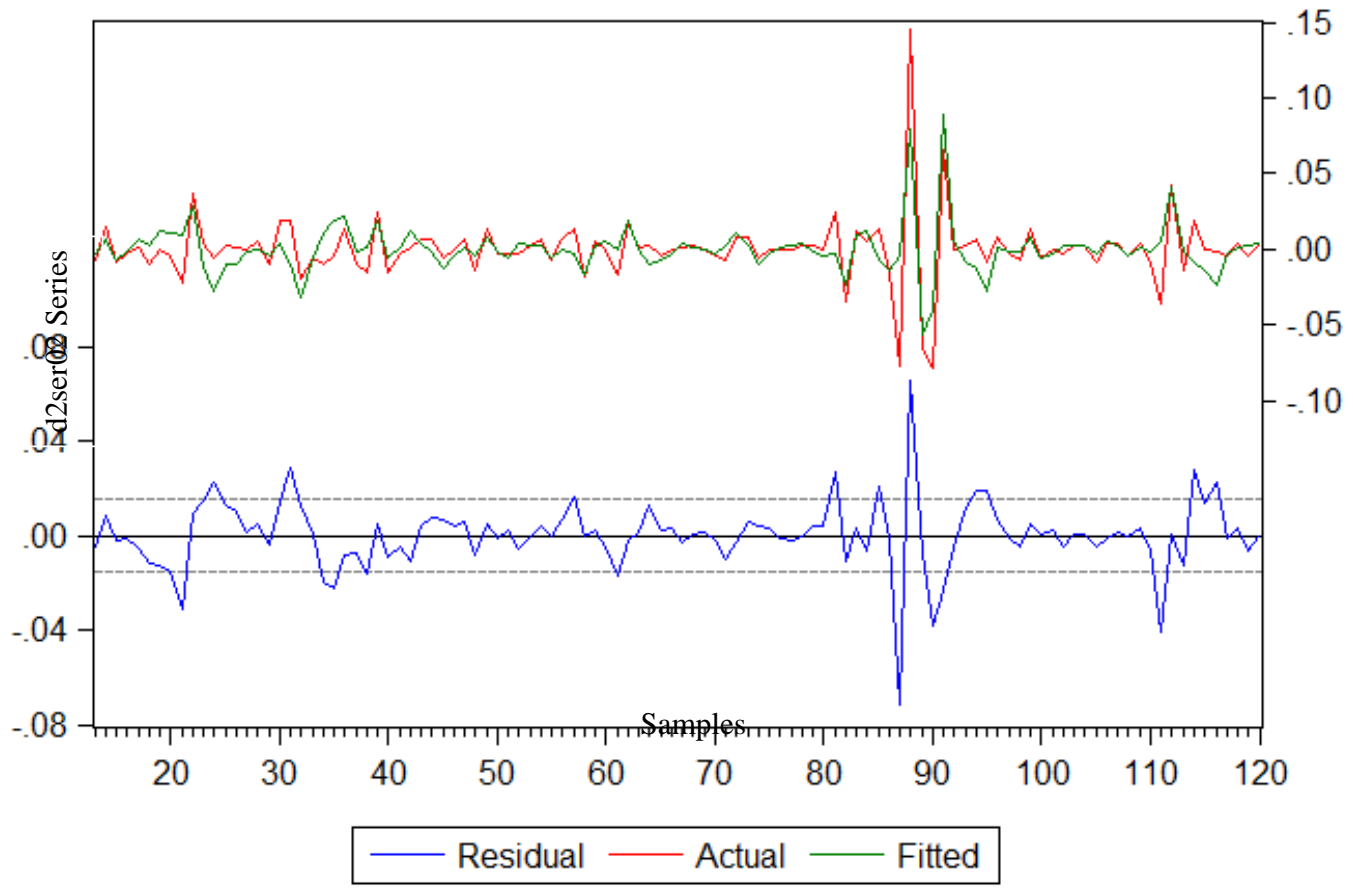

Figure 9 SARIMA(4, 2, 0)(0, 1, 0) ${ }^{10}$ Model fitting diagram

\section{Comparison Between Multiple Regression Model and SARIMA Model}

SARIMA(4, 2, 0) $(0,1,0)^{10}$ model is used to forecast the total retail sales of consumer goods from march to November in 2019. In order to improve the prediction accuracy, this paper adopts the static rolling prediction method, which uses the data from March 2007 to December 2018 firstly to predict the data of March 2019, and then the new time series is used to build a model to predict April 2019, and so on. The prediction effect of the model is shown in Figure 10. 


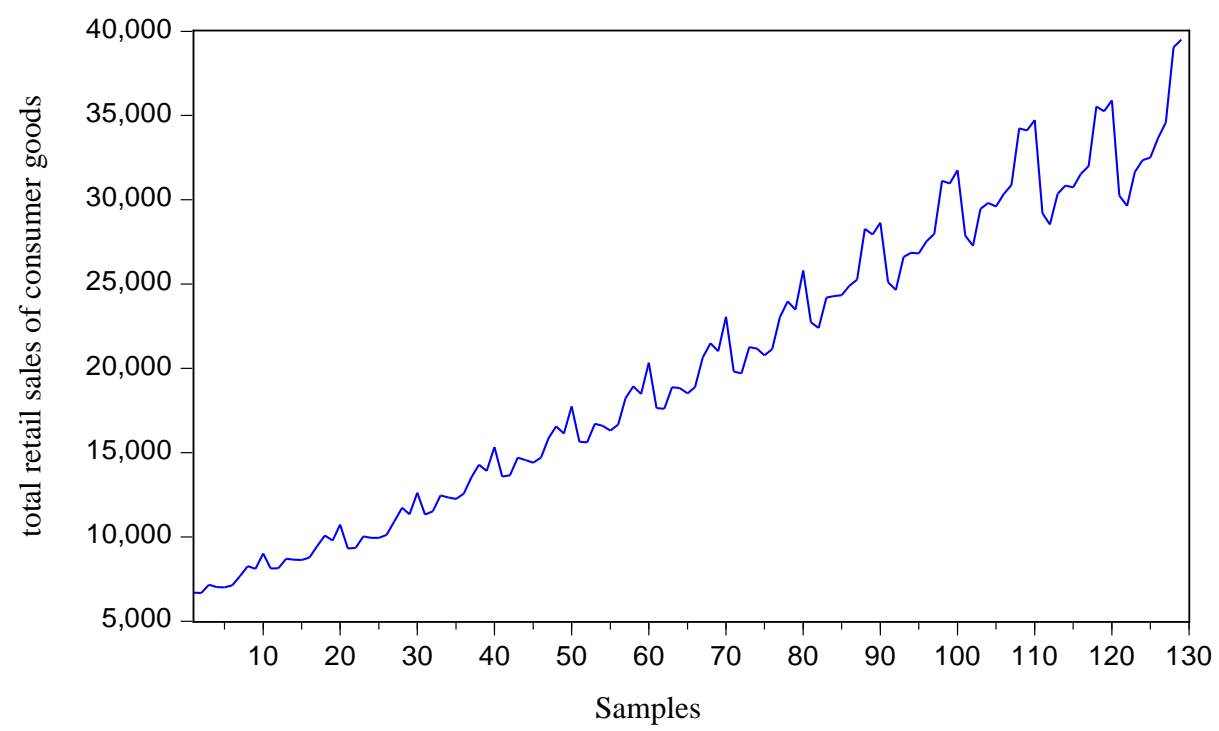

Figure 10 Actual value and forecast value from March 2007 to November 2019

Use the multivariate regression equation $Y=458.047+0.017 X_{1}+0.083 X_{2}$ and SARIMA (4, 2, $0)(0,1,0)^{10}$ model on November 3, 2019 social total retail sales of consumer goods to predict respectively, with the result summarized in Table 10.

Table 10 Data model fitting case

\begin{tabular}{|c|c|c|c|c|c|}
\hline \multicolumn{2}{|c|}{ Model } & Multiple regression model & \multicolumn{2}{c|}{ SARIMA model } \\
\hline Time in 2019 & Actual values & Fitting values & Error & Fitting values & Error \\
\hline March & 31725.70 & 34679.20 & $9.31 \%$ & 30241.51 & $-4.7 \%$ \\
\hline April & 30586.10 & 33911.60 & $10.87 \%$ & 29639.70 & $-3.09 \%$ \\
\hline May & 32955.70 & 34048.21 & $3.32 \%$ & 31639.59 & $-3.99 \%$ \\
\hline June & 33878.10 & 35653.92 & $5.24 \%$ & 32347.76 & $-4.52 \%$ \\
\hline July & 33073.30 & 34285.31 & $3.66 \%$ & 32505.97 & $-1.72 \%$ \\
\hline August & 33896.30 & 34615.22 & $2.12 \%$ & 33666.64 & $-0.68 \%$ \\
\hline September & 34494.90 & 35766.37 & $3.69 \%$ & 34589.45 & $0.27 \%$ \\
\hline October & 38104.30 & 34527.18 & $-9.39 \%$ & 39039.81 & $2.46 \%$ \\
\hline November & 38093.80 & 35120.06 & $-7.81 \%$ & 39492.92 & $3.67 \%$ \\
\hline
\end{tabular}

The predictive power of the model is generally measured by MAPE (mean absolute percentage error):

$$
M A P E=\frac{1}{n} \sum_{i=1}^{n}\left|\frac{\hat{x}_{i}-x_{i}}{x_{i}} \times 100\right|
$$

In MAPE formula, $\hat{x}_{i}$ is the forecast model, $x_{i}$ is the actual value, and $\mathrm{n}$ is forecast periods.

The model has excellent predictive ability when MAPE is less than or equal to $10 \%$. The prediction ability is good at $10 \%-20 \%$ and is reasonable at $20 \%-50 \%$. Prediction is inaccurate when MAPE is above $50 \%$. According to the above analysis, the MAPE value of the multiple regression model in the period from March to November 2019 is 5.54\%, and the MAPE value of SARIMA(4, $2,0)(0,1,0)^{10}$ model in the same period is $2.51 \%$, both in the "excellent" range.

Based on the above comparative analysis, $\operatorname{SARIMA}(4,2,0)(0,1,0)^{10}$ model is used to forecast the current value of the total retail sales of consumer goods from march to December 2020, and the interval estimations at 95\% confidence level have been made. The results are shown in Table 11. 
Table 11 Forecast value of total retail sales of consumer goods

\begin{tabular}{|c|c|c|c|}
\hline Time in 2019 & Point estimation & $\begin{array}{c}\text { 95\% lower } \\
\text { confidence limit }\end{array}$ & $\begin{array}{c}\text { 95\% upper } \\
\text { confidence limit }\end{array}$ \\
\hline March & 34344.05 & 32496.39 & 36268.83 \\
\hline April & 32860.49 & 30741.17 & 35086.73 \\
\hline May & 35377.55 & 32775.45 & 38130.44 \\
\hline June & 36665.02 & 33675.62 & 39847.65 \\
\hline July & 35485.60 & 32336.81 & 38857.20 \\
\hline August & 36384.38 & 32915.52 & 40118.37 \\
\hline September & 37031.60 & 33274.06 & 41096.30 \\
\hline October & 40828.10 & 36451.09 & 45584.93 \\
\hline November & 40900.25 & 36294.29 & 45927.92 \\
\hline December & 41632.08 & 36730.26 & 47005.11 \\
\hline
\end{tabular}

\section{Conclusions and Policy Recommendations}

Through the analysis above, we can see that both the multiple regression model and SARIMA(p, $\mathrm{d}, \mathrm{q})(\mathrm{P}, \mathrm{D}, \mathrm{Q})^{\mathrm{S}}$ model can play an important role in the prediction of total retail sales of consumer goods in China. In the short term, SARIMA(p, d, q)(P, D, Q $)^{S}$ model has a high reliability for the forecast of total retail sales of consumer goods and a small error rate between the predicted value and the real value. The model's error increases over time, so we can use it to provide short-term forecasts and policy guidance.

The results of multiple regression show that the factors that have a greater impact on the total retail sales of consumer goods are money and quasi-money stock (M2) and national budget fiscal expenditure, while the linear relationship between the total retail sales of consumer goods and money and quasi-money stock is the strongest. Regression equation for $Y=458.047+0.017 X_{1}+$ $0.083 X_{2}$. With other factors unchanged, for every 100 million yuan increases in $\mathrm{M} 2$, total retail sales of social consumer goods increases by an average of 1.7 million yuan. For every 100 million yuan increase in the state budget, the total retail sales of consumer goods will increase by an average of 8.3 million yuan. The results show that under the current circumstances, China's monetary policy is not completely neutral, and the accurate supply of money can enhance China's consumption vitality.

To sum up, based on the coordination and cooperation of the steady monetary policy and active fiscal policy corresponding to the money supply and fiscal expenditure, as well as the continuous promotion of supply-side reform in various fields, the total retail sales of consumer goods in China will continue to maintain a rapid growth trend. As a result, the people's living standards will be further improved.

\section{References}

[1] Minmin Ma. The landing point of China's consumption-led economy -- an interview with Zhengsheng Zhong [J], Financial expo (wealth), 2019, (12): 14-17.

[2] James Menzies. Consumers driving U.S. economy, as business investment stalls: FTR [J]. Truck News, 2020, 39(12).

[3] Fa Lina. Empirical Analysis on the Sustainable Growth of China's Total Retail Sales of Consumer Goods, 2010, (05): 32-35.

[4] Bing Peng, Jianting Hu, Jie Deng. An empirical analysis of the factors influencing the total retail 
sales of consumer goods in the Yangtze river delta [J]. The knowledge economy, 2012, (02): 93.

[5] Deyin Chu, Wei Yan. Tax policy and consumer demand: a new thinking from the perspective of structural effects [J]. Economic theory and economic management, 2012, (03): 53-63.

[6] Xuepei Xiao. Model and forecasting of total retail sales of consumer goods by the seasonal ARIMA model [J]. Science and technology economic market, 2019, (04): 63-65.

[7] Long Wu. Principal component regression analysis of influencing factors of total retail sales of consumer goods [J]. Development and reform theory and practice, 2017, (10): 49-51.

[8] Lina Fa. Empirical analysis of the continuous growth of the total retail sales of consumer goods in China [J]. Economic problems, 2010, (05): 32-35.

[9] Zhijian Wang, Binhui Wang. Total retail sales forecast of consumer goods based on the ARMA model [J]. Statistics and decision-making, 2014, (11): 77-79.

[10] Xiaofeng Zhang, Bo Li. Application of the ARIMA model in total retail sales forecasting [J]. Modernization of shopping malls, 2007, (32): 55-56.

[11] Huachu Zhang, Hong Lin. ARIMA forecasting model of retail sales of consumer goods in China [J]. Statistical research, 2006, (07): 58-60.

[12] Baohui Li. Research and prediction of the law of social consumable index with time-series model [J]. Statistical research, 2000, (01): 53-55.

[13] Bing Peng, Jianting Hu, Jie Deng. An empirical analysis of the factors influencing the total retail sales of consumer goods in the Yangtze river delta [J]. Knowledge economy, 2012, (02): 93.

[14] Dong Pan, Changfeng Shi. Method and application of total retail sales forecasting in China [J]. Statistics and decision-making, 2015, (13): 96-98. 